\title{
La filosofía colonial de los siglos XVII y XVIII: ¿nuestra tardía Edad Media?
}

\author{
Joaquín Zabalza I*
}

\section{Introducción}

Por estas fechas, hace veinte años, se reunía en la sala de consejos de esta Universidad un grupo numeroso de filósofos, miembros de la Academia de Historia, de la Academia de la Lengua y del Instituto Caro y Cuervo, con el fin de determinar el pensum de la Facultad de Filosofía que se pretendía fundar. Entre los presentes se hallaba un extranjero. En las últimas sesiones, cuando ya la programación de las materias y los contenidos generales de las mismas estaban casi totalmente configurados, el extranjero anotó la ausencia de una materia o de un capítulo extenso dentro de la historia de la filosofía que se denominara Historia de la Filosofía Colombiana o Historia de la Filosofía en Colombia o algo similar, e insistió en que se llenara ese vacío. Al fin de las deliberaciones la propuesta fue rechazada (un voto a favor y todos los demás en contra) porque prevaleció la tesis de que en Colombia nunca se había cultivado la filosofía de una forma tal que mereciera el esfuerzo de su estudio y recuperación.

Sin duda, ese extranjero que estaba recién "desempacado", pues no llevaba sino un año de presencia en Colombia, conservaba todavía la psicología del turista; esta y no ningún don de clarividencia, fue la que le había impulsado a hacer su propuesta.

En los años siguientes el extranjero pudo ir constatando meritorios esfuerzos y realizaciones en pro de la reconstrucción del pasado filosófico de Colombia.

\footnotetext{
* Artículo publicado en Cuadernos de Filosofía Latinoamericana, No. 26, enero-marzo, 1986. pp. 9-14.
} 
En los cuatro o cinco últimos años el extranjero del cuento ha tenido contactos permanentes con el Centro de Documentación e Investigación de la Facultad de Filosofía de la Universidad Santo Tomás, especialmente con los profesores Germán Marquínez Argote y Rafael Pinzón Garzón. Algo de lo que vio y algo de lo mucho que le contaron es lo que aparece transcrito en las líneas siguientes. Lo que se dice tómenlo ustedes con la misma benevolencia con la que se acogen las apreciaciones de un extranjero, con beneficio de inventario turístico. Máxime porque nos vamos a centrar en el periodo más oscuro de nuestra historia, sobre el cual los investigadores están todavía dirigiendo las primeras luces.

La historiografía liberal de la segunda mitad del siglo XIX, para marcar su ruptura con el orden colonial, llamó a este "nuestra tardía Edad Media". Dejando a un lado lo que esta expresión pueda tener de negación y desprecio, es claro que mienta una analogía con un fondo de verdad que en estas páginas me propongo explicitar.

Como es sabido, los términos análogos se predican de sus analogados en parte igual y en parte desigual. Participan, por consiguiente, en alguna medida de la univocidad y de la equivocidad, dos extremos entre los cuales se sitúa y bascula el pensar analógico. Se comparan, pues, dos edades distintas y distantes en el espacio y en el tiempo, pero que tienen algo en común y que, por lo mismo, llamamos "Edad Media". Los adjetivos "nuestra" y "tardía" se relacionan a un espacio geográfico y a un tiempo histórico que no coinciden con los del analogado principal, pero que, por dependencia histórica, participan de ciertos caracteres de la Edad Media sin más. El pensar analógico es legítimo; más aún, puede ser un método conveniente de comprensión del devenir histórico, siempre y cuando no se caiga en simplificaciones de tipo univocista que borren las diferencias.

Pero el problema de dicha analogía se complica si tenemos en cuenta que nuestra llamada Edad Media, al menos en cuanto se refiere a las prácticas filosóficas, depende, así mismo, de la segunda escolástica española. Por consiguiente, la expresión que analizamos: "nuestra tardía Edad Media", designa una analogía de segundo grado, esto es, analogía de analogía.

Existe en la comparación establecida tres analogados: la Edad Media sin más, la segunda escolástica española y nuestra tardía Edad Media. Es necesario caracterizarlas en lo que tienen de común y en sus diferencias para no caer en interpretaciones simplistas. Sería un simplismo que atinadamente denunció Fabio Ramírez, S. J., en el último Congreso Internacional de Filosofía Latinoamericana, concluir a priori que 
si la Edad Media sin más fue "así” o que si la segunda escolástica fue "así”, nuestra escolástica tardía debió ser "así” o "asa”. Si existe un fundamento para establecer la analogía, además de las semejanzas habrá que tener presentes las diferencias. Estas últimas también pertenecen a la esencia de la analogía y habría que establecerlas en forma documentada, ateniéndose a la investigación historiográfica y más allá de fáciles esquemas caracterizadores que dispensan del trabajo investigativo y a la postre deforman la historia. La analogía en cuestión salta tres espacios y tiempos distintos que constituyen a mi modo de ver tres horizontes irreductibles. Veámoslos.

\section{Tres horizontes distintos}

a. Primero, el horizonte de la filosofía medieval. La escolástica, de schola, fue el saber cultivado en las escuelas cristianas de la Edad Media bajo la dirección de un maestro o scholasticus. Las escuelas fueron, en un primer momento, monacales, después palatinas y catedralicias, y por último verdaderas universidades. En ellas se enseñaban las verdaderas artes, que incluían el Trivium (gramática, retórica y dialéctica) y el Quatrivium (aritmética, geometría, astronomía y música), pensum heredado de la antigüedad clásica, y que constituía la antesala para el estudio de la teología. Esta era la ciencia primera, scientia prima, a la cual se subordinaban todos los demás estudios. A su vez la teología necesitaba del saber filosófico para su desarrollo, porque el espíritu medieval no se contentaba con recibir de la iglesia las verdades reveladas. Aspiraba a penetrar su sentido profundo y a suministrar explicaciones de las mismas, que si bien no disipan la oscuridad esencial de los misterios, al menos eliminaban sus aparentes contradicciones y los hacía creíbles. Por lo mismo, la escolástica constituyó un método tendiente a la explicación racional de los dogmas: "explicatio fidei”. El ideal de esta explicación de la fe lo expresó San Anselmo en su conocida frase: "Fides quarens intellectum", la fe que busca ser entendida; que traduce la igualmente famosa expresión de San Agustín: "Intelligo, ut credam, credo ut intelligam”, entiendo para creer, creo para entender, entender para creer, creer para entender. En esas condiciones, la filosofía en la Edad Media se cultivó en función de la teología, no en sí ni por sí misma. El horizonte de las prácticas filosóficas fue teológico. Por ello se dice y repite que su función fue ancilar, acilla theologiae.

En el largo proceso de la filosofía medieval se acostumbra a distinguir cuatro etapas: $1^{\mathrm{a}}$. De formación (ss. IX-XI), 2a . De desarrollo (s. XII), 3a . De apogeo (s. XIII), 4a . De decadencia (ss. XIV-XV). 
En las dos primeras, supuesto el aprendizaje de las “artes”, se comentaban básicamente las Sagradas Escrituras, sacra página, a la luz de las interpretaciones de los padres griegos y latinos, con ayuda de la dialéctica o lógica aristotélica plenamente recuperada en el siglo XII. En cuanto a contenidos filosóficos se refiere, dentro de esta primera especulación teológica existe un amplio y profundo influjo de elementos neoplatónicos (más que del mismo Platón) que llegan a la Edad Media por diversos conductos: Calcidio, Proclo, Boecio, el seudo Dionisio y sobre todo San Agustín, quien influye profundamente en San Anselmo, en Escoto Erígena y en Abelardo, tres grandes maestros de la "alta Edad Media".

Pero en el siglo XIII, el del apogeo de la escolástica, tienen lugar hechos decisivos. El primero de ellos lo constituye la recuperación de Occidente de la obra completa de Aristóteles, el Corpus Aristotelicum, gracias a los buenos oficios de la escuela de traductores de Toledo, ciudad en la que convergían tres culturas: cristiana, árabe y judía. Los árabes dieron a conocer al occidente cristiano el pensamiento completo del Estagirita, comentado a su vez por sus grandes filósofos, como Averroes y Avicena. Dicha recepción no se hizo sin acaloradas controversias e incluso precipitadas condensaciones, pese a las cuales, entrando en el siglo XIII, Aristóteles terminó imponiéndose como nueva autoridad filosófica, aunque su hegemonía no fuera absoluta, como se cree, ni siquiera en la Orden Dominicana. Al iniciarse el siglo XIII tiene lugar otro hecho de singular importancia, el nacimiento de las universidades, universitas magistrorum et schoolarium, siendo la de París la más importante. Por otra parte, y este es el tercer hecho, a las universidades se incorporan desde su misma fundación las dos nacientes órdenes mendicantes: Franciscanos y Dominicos, contribuyendo en forma decisiva a elevar el nivel académico. La segunda mitad del siglo XIII conoce la emergencia de los grandes maestros: Buenaventura, Alberto Magno, Tomás de Aquino, Duns Escoto, que crean y consolidan al interior de la escolástica dos tradiciones distintas y discrepantes que conocemos como tomismo y escotismo. Las dos escuelas asumen en buena medida el legado filosófico de Aristóteles, dando la franciscana ciertamente más cabida a elementos platónicos que la tomista. Pero también en esta se conservaron numerosos elementos de la tradición platónica y agustiniana que equilibraron las nuevas y decisivas influencias peripatéticas.

A las antiguas prácticas y géneros literarios, como la lectio y la disputatio, se sumaron los commentaria, las questiones, los opuscula y, hecho fundamental, las grandes Summae, en cuya arquitectura, aunque teológica, se incorporó todo el saber filosófico de la época. Las Summae, las grandes creaciones del espíritu medieval, reflejan un 
modo de vida teocéntrico, como en la literatura la Divina Comedia de Dante, contemporáneo de Santo Tomás. Sería injusto calificar de "bárbara” una cultura que produjo tales obras, aunque la nuestra, secularizada, sea tan distinta y por ello a muchos no guste aquella. Habría que añadir que frente a la alta Edad Media campesina, feudal y monacal, el siglo XIII es el del Renacimiento de los burgos, en los cuales se impone un modo de vida más liberal y secularizado con el nacimiento de los gremios que prosperan a la sombra de las catedrales y de las universidades. La Universitas era, a su vez, el gremio de los maestros y discípulos cuya agitada vida intelectual aun hoy nos sorprende por su carácter innovador y democrático. En relación con la filosofía, si bien es cierto que no se cultivó ni siquiera en el siglo XIII por sí misma, ello no significa que no se tuviera claro el concepto de la especificidad de ambos saberes, el racional y el revelado.

En los siglos XIV y XV, periodo de decadencia, la escolástica se fragmenta y pierde su impulso creador anterior, al tiempo que el ideal de cristianidad, concebida como agrupación de los pueblos cristianos bajo la autoridad temporal del Emperador y la espiritual del Romano Pontífice entra en crisis. En filosofía se impone el nominalismo, cuya máxima figura fue Guillermo de Ockaham, perteneciente a la escuela franciscana. El nominalismo constituye el puente entre la vía antigua y la vía modernorum, circunstancia esta que le confiere una importancia histórica de primer orden.

b. El segundo horizonte, que intentaré caracterizar brevemente, es el de la segunda escolástica española, más próxima y de influencia más inmediata sobre nuestra llamada Edad Media o filosofía colonial. Tal como se dio en España en los siglos XVI y XVII no fue una mera repetición de la primera, y no podía serlo porque no en balde el horizonte había cambiado profundamente. Ya en el siglo XV los humanistas se vuelven contra la escolástica decadente, agotada y desvitalizada; le reprochan ser una maraña de cuestiones abstrusas e inútiles y el uso bárbaro de la lengua latina. Por influencia de los humanistas, los escolásticos del siglo XVI recuperan el vigor y la perfección de la forma y se desentienden de cuestiones baladíes. Se imponen de nuevo como obras de estudio los clásicos del siglo XIII, en especial la Summa Theologica de Santo Tomás, pero no para repetirlos sino para recrearlos y aplicar sus doctrinas a los nuevos problemas. Hecho decisivo de estos nuevos tiempos fue el descubrimiento y la conquista del Nuevo Mundo. Los problemas que suscitaron van a constituir tema central y apasionado de discusiones teológicas, filosóficas y jurídicas durante el siglo XVI, cuyas doctrinas, sistematizadas en los grandes tratados De legibus, De iustitía et iure, echaron las bases sólidas del derecho de gentes o ius gentium. 
Hoy nadie pone en duda la importancia de primer orden de Francisco de Vitoria y su escuela. Gracias a su magisterio y a las reformas introducidas por él, Salamanca desplaza en importancia a París. Por otra parte, a las antiguas órdenes mendicantes se une ahora otra de carácter militante, la Compañía de Jesús, que irrumpe con fuerza en los claustros universitarios y que pronto reconoce en Francisco Suárez una nueva cabeza de escuela, que se llamará suarismo o suarecianismo. Como lo ha reconocido Heidegger, en Ser y Tiempo, Suárez sirve de gozne entre el pensamiento medieval y el moderno. Sus Disputationes Metaphisicae, son la primera Suma o cuerpo de filosofía, en la que esta se independiza de los marcos teológicos y adquiere real autonomía. El florecimiento de la segunda escolástica española es contemporáneo de la edad de oro de las letras castellanas. Vitoria es contemporáneo de Fray Luis de León y Suárez de Cervantes. Es verdad que a la muerte de Suárez la escolástica española entra rápidamente en decadencia, así como otras manifestaciones de la cultura española, y la misma España en cuanto a primera potencia imperial. En el siglo XVII, la controversia de auxiliis, polarizada por Bañez y Molina, apasionó al hombre barroco. Pero el horizonte de la segunda escolástica ya es por muchos aspectos un horizonte humanista o al menos no enteramente teológico, como sí lo había sido el de la Edad Media. Un hecho que contribuyó en parte a estrechar tan promisorios desarrollos fue el de la contrarreforma católica proclamada en Trento como respuesta a la reforma protestante. La cultura española, tan viva en el siglo XVI, se sitúa en el XVII en posición defensiva. España, frente a los peligros que vienen del exterior, se "tibetiza" en defensa de la fe y del imperio, colocándose al margen de los avances de la nueva ciencia.

c. Pasemos al tercer horizonte: nuestra tardía Edad Media. La época colonial que abarca los siglos XVII y XVIII es, efectivamente, una edad "media", porque media entre el siglo XVI de las conquistas y el siglo XIX de la emancipación de España y de la constitución de nuevas repúblicas independientes. Entre un siglo heroico y un siglo glorioso nos hemos acostumbrado a ver el siglo XVII (en parte el siglo XVIII) como el de la siesta colonial, como tiempo oscuro en el que no hubiera pasado nada.

Pero la expresión "Edad Media" se dice de este periodo de nuestra historia, no solo por ocupar un puesto intermedio entre dos siglos, sino también por sus características internas que en bastantes aspectos recuerdan las de los analogados anteriores. No obstante, es necesario insistir en la diferencia del nuevo horizonte colonial.

La Nueva Granada en los siglos XVII y XVIII tiene un carácter periférico y colonial. Como colonia es una pequeña parte de un inmenso imperio que se extiende en 
América desde California hasta la Tierra del Fuego. Dentro del mismo, ni la Real Audiencia de Santa Fe, ni más tarde el virreinato tuvo nunca la importancia de otros centros administrativos y culturales como México y Lima. Y pese a ocupar mayor extensión que la actual Colombia, el Nuevo Reino entrado en el siglo XVIII no sobrepasaba en mucho el millón de habitantes. Santa Fe, la capital virreinal, aunque con rango de ciudad, como otros centros urbanos menores, era en realidad una aldea a fines del siglo XVIII, que alcanzó a tener 28.000 habitantes o almas según los cómputos de la época. Sobra pues toda comparación con París del siglo XVII o con la Salamanca plateresca del siglo XVI. Y sin embargo, en esta pequeña ciudad andina, a 2.600 metros de altura sobre el nivel del mar, las cátedras de filosofía no las desempeñaban los ángeles, como alguna vez se le ocurrió pensar a Ortega y Gasset cuando en 1936 le ofreció una la Universidad Nacional. En ella, a los pocos años de su fundación, se establecieron dominicos, franciscanos, agustinos y jesuitas, órdenes que detentaban el saber de la época.

Como en la Edad Media la educación seguía en manos de la Iglesia. Fueron, pues, las órdenes religiosas las que abrieron las primeras escuelas de gramática y demás artes y las que al promediar en el siglo XVII fundaron las universidades, siguiendo el modelo de Salamanca, Universidad por la época desgraciadamente en franca decadencia. Durante el siglo XVII funcionaron en Santa Fe dos universidades de derecho pontificio y real, la Santo Tomás y la Javeriana, con otros colegios mayores anexos a las mismas, como el del Rosario, San Bartolomé y San Buenaventura. A principios del siglo XVIII nace una nueva Universidad, de corta duración, la de San Nicolás de Bari, regentada por agustinos. Sorprende la profusión de centros superiores de educación en la colonia Santa Fe, ejemplo de minifundio universitario imitado por la Bogotá actual.

El horizonte de las prácticas filosóficas en los claustros coloniales dependía de las características del imperio español y de sus necesidades fundamentales en las colonias. Era un imperio que había asumido del papado el encargo y la responsabilidad de la evangelización, labor que realizaba fundamentalmente gracias a las órdenes religiosas, bajo el control del Patronato Regio. En los documentos fundacionales de las universidades aparece claro este propósito misional que no se da en las universidades europeas. En segundo lugar, la Iglesia y la monarquía consideraban la unidad de la fe como el mayor bien que había que defender frente a los peligros de división o herejía. Para ello, la monarquía había asumido las conclusiones del Concilio de 
Trento y trató por todos los medios de implantarlas. En tercer lugar, tan dilatado imperio necesitaba, además de unidad religiosa, unidad política y administrativa con la distante metrópoli que se logró mediante la creación de gobernaciones, reales audiencias y virreinatos, instancias supremas en América, de las que dependía todo el aparato administrativo de las colonias.

Las universidades, pues, tenían como objetivos fundamentales satisfacer dichas necesidades formando sujetos idóneos. De aquí que, además del curso preliminar y obligatorio de "artes" (entre las que se incluía el estudio de la filosofía), las universidades ofrecieran en las facultades mayores estudios de teología y de derecho, tanto canónico o religioso como civil. Tardíamente se abrió en el Rosario la cátedra de medicina. Huelga decir que el pensum en dichas facultades era el mismo que el de la Universidad de Salamanca, y que de acuerdo con los anteriores objetivos se mantuvo la dependencia ancilar de la filosofía con respecto a la teología, aunque era enseñada como una disciplina autónoma.

\section{La universidad colonial por dentro}

Me voy a referir brevemente al espacio físico, a los alumnos, a los profesores, a la organización y métodos, a los diversos partidos o escuelas y finalmente a la producción escrita.

El espacio físico en el que funcionaron las universidades eran los mismos conventos de las órdenes religiosas que las regentaban, con sus iglesias, aulas y claustros: Santo Domingo, El Rosario, San Ignacio, San Francisco, La Candelaria, allí tuvieron sede los colegios universitarios y las universidades; de aquí la identificación de Universidad con claustro. Se continuaba así la tradición medieval de una universitas constituida por diferentes colegios federados de acuerdo a las diversas tradiciones o escuelas.

La población universitaria o alumnado podía alcanzar grandes proporciones. Ni la población total del virreinato, ni los recursos económicos del Nuevo Reino (que no eran los de México o Perú), ni las restricciones que se imponían para el ingreso por razón del sexo o la casta, lo permitían. Las mujeres, solo avanzado el siglo XVIII, pudieron ascender en el Nuevo Reino a los rudimentos de la educación en colegio propio para ellas. Esto acontecía por igual en Europa. Las mujeres que en Europa o América sobresalieron en las letras, fueron casos excepcionales de autodidactas, como 
la Madre Josefa Castillo o Sor Juana Inés de la Cruz. El caso de Teresa de Jesús en España es también excepcional. En una sociedad, además de machista, estratificada en castas, como la del siglo XVII (en parte la del XVIII) solo los peninsulares o criollos de origen blanco tenían la posibilidad de ascender a los estudios superiores, siempre y cuando los segundos demostraran limpieza de sangre o "no estar manchados de tierra”. En caso de mestizaje comprobado o evidente, se podía ganar tal honor por méritos reconocidos por las autoridades, cosa que en el siglo XVIII se fue haciendo más fácil. Además, por los mismos objetivos de las universidades, la mayor parte de los candidatos, desde los estudios de artes, se encaminaba hacia el sacerdocio, quedando como carrera específica para seglares de las leyes. La fundación del Colegio del Rosario se debió en parte para dar más cabida a seglares, y gracias a este claustro se pudieron graduar buena parte de nuestros precursores y emancipadores. Tenemos algunas estadísticas de graduados en las dos universidades, por las que podemos deducir que el número de estudiantes no fue en efecto grande, pero sí importante en relación al número de habitantes. Juan Martínez de Ripalda, catedrático eminente y rector de la Javeriana, afirma que desde su fundación en 1621 hasta 1704 la Academia Xaveriana había graduado "ciento veinte doctores en teología" y "cuatrocientos doce maestros en filosofía", lo cual constata con legítimo orgullo en estos términos:

Se gloriaba en cierta ocasión Ciro el Menor, Rey de los Persas, de que pudiera responder a Lisandro Lacédemonio, cuando este admiraba el orden y la corpulencia de los árboles que adornaban el regio jardín: "muchos de estos árboles fueron plantados con mis manos", pues no juzgaba indigno de su majestad real llamarse campesino, y entre los campesinos ser tenido como rey. Con cuánta mayor razón hay que decir de vosotros eminentísimos padres (de la Academia Javeriana), que brilláis en el supremo solio de la sabiduría, como Reyes entre los sabios, lo siguiente:

Todas estas laureas con vuestras manos fueron plantadas, con vuestra industria cultivadas, con vuestros sudores nutridas. Esta tarea de vuestros estudios está guiada con cuidado y empeño. Nada más digno, pues, que vuestra sabiduría, con la que hacéis a los sabios semejantes a vosotros. Recorred así todas las provincias del Nuevo Reino y reconoced vuestras laureas: unas entretejidas con sagrados aderezos, y otras ostentando muy ilustres togas; las hay que orientan a los pueblos con la santidad de las costumbres y con el pasto de la doctrina en los templos, otras que desde los tribunales moderan las ciudades 
con la equidad de las leyes y con la integridad incorrupta del derecho. Todas, finalmente, adornadas con singular piedad y con la munificencia de la esplendidez real. Es tan grande tu gloria (Academia Xaveriana), que esta revierte a los que cultivan tu heredad (Martínez de Ripalda, 1704)ํ․

Esta laudatío la dirige Ripalda a los 532 javerianos graduados y a sus catedráticos durante ochenta y tres años del siglo XVII.

Por su parte, la Universidad tomista, durante el período 1768-1808 en que la Javeriana estuvo cerrada por la expulsión de los jesuitas en 1767, graduó un total de 2.070 alumnos, distribuidos así: 1.264 bachilleres, 390 licenciados, 397 doctores, 23 maestros en las diversas facultades existentes. Por lo que hace a la filosofía: 728 bachilleres, 24 licenciados, 12 doctores y 28 maestros $^{2}$.

Estas cifras responden en casi su totalidad al siglo XVIII, lo cual permite concluir que la población universitaria en este siglo, sin ser masiva, fue relativamente grande con respecto al número de habitantes del Nuevo Reino. Santa Fe, desde luego, debió lucir una alta concentración de graduados. En una pequeña ciudad como era, sin mayores diversiones, los actos académicos y religiosos tuvieron por ello singular relieve y pompa, y era esta la ocasión que tenían los bachilleres, maestros, licenciados y doctores para lucir sus insignias y preseas.

1 Martínez de Ripalda, Joannes, De usu et abusu doctrinae Divi Thomae. Leodi, Apud Guilielmum Streel, MDCCIV, "Epistola Dedicatoria". Hay que anotar que no se trata del homónimo Juan Martínez de Ripalda (1594-1648), nacido en Pamplona, España, profesor de Salamanca y reputado coma uno de los mejores teólogos de su tiempo en Europa y que escribió la celebérrima obra: Disputationes theologicae de ente supernaturali (1634). El nuestro, Juan Martínez de Ripalda (1646-1727), nació en Olite, Navarra, y murió en Madrid, habiendo sido catedrático en Bogotá y Quito. Posiblemente, ambos fueron familiares (¿tío y o sobrino?). Del nuestro, escribe a. J. J. Urraburu: "P. Joannes Martínez de Ripalda, non ille clarissimus auctor praestantissimi operis de Ente supernaturali; sed alter, hispanus et ipse et coterraneus prioris, Professor et Rector Collegii Sanctae Fidei in novo Regno Granatensi in America"; cf. Joannes Josephus Urraburu, Institutiones Philosophicae, vol, VIII; Theodicea. Vallisoleti, Typis Joseph Emmanel a Cuesta, 1900, t. 2, p. 894 (agradezco esta información al P. Fabio Ramírez).

2 Libro de propinas Mandado hacer por el M.R.P. Predicador Frai Antonio Cabrejo, Rector de este Collegio y Universidad del Angélico Maestro Santo Thomás de esta ciudad de Santa Fe, por el mes de julio del año 1768. Manuscrito conservado en la Biblioteca Nacional, sección de libros raros y curiosos. Sala de seguridad 145. Cf. el estudio del mismo: Molina Ruíz, Esperanza, "Ochocientos titulados en Filosofía entre 1768-1808", en Cuadernos de Filosofía Latinoamericana, Bogotá, 21 (1982), pp. 25-51. 
En cuanto al origen de los catedráticos, parece que predominaron los de procedencia peninsular, seguidos en neogranadinos, peruanos y algunos de otros países europeos. Una prueba de ello es que de los manuscritos conservados: 72 son españoles, 51 neogranadinos, 6 peruanos y 113 de procedencia desconocida; el más eminente de todos ellos fue, sin duda, el español Juan Martínez de Ripalda (cf. nota 1), catedrático y rector de la Javeriana, quien escribió en Santa Fe un curso completo de filosofía y de teología, que mereció los honores de la publicación en Lieja en 1704, bajo el título De usu et abusu doctrínae Sancti Thomae. Hasta 1706 todos los catedráticos javerianos pertenecían, sin excepción, a la Compañía. Después de esta fecha admitieron a extraños, siendo la única Universidad en la que regentaron cátedras religiosas no españoles: como alemanes, flamencos, italianos y franceses. Caso singular es el discípulo de Descartes, Denis Mesland, quien dictó clases en la Javeriana en vida de Descartes y murió en Bogotá (Pacheco, 1971, pp. 273-283).

Las cátedras las regentaban religiosos, excepto las de leyes o derecho civil que corrían a cargo de profesores seglares. A las mismas se ascendía por riguroso examen de oposición formal, según reglamentos. Por los manuscritos redactados por los propios profesores, o copiados de sus explicaciones por los alumnos, podemos deducir acerca de la seriedad con que se tomaba la preparación de las clases. A los catedráticos les competía los derechos de precedencia, asistencia o exámenes, voz en el claustro o consejo universitario; recibían emolumentos, que llegaban hasta 250 pesos anuales por la cátedra de leyes, menores en las otras. En caso de muerte las honras fúnebres las costeaba la Universidad. Perdían la cátedra por incompatibilidad con otros oficios o beneficios, por inasistencia durante más de treinta días consecutivos, o por negarse a defender la inmaculada concepción de María, entre otras causales.

La metodología giraba en torno a la lectio y la disputatio, La lección o la lectura de los textos de maestros que constituían verdaderas autoridades en la materia (Aristóteles, Tomás, Cano, Soto, Suárez, etc.) era la primera obligación del catedrático, que por ello se llamaba lector. A la lectura ritual de los textos consagrados seguía la dictatío o comentario. Al alumno por su parte, en el proceso enseñanza-aprendizaje, le correspondía la copia fiel de los comentarios del catedrático y la memorización de los mismos con ayuda de pasantes y del propio estudio personal en la celda o meditulio. Supuesto lo anterior, diariamente había un tiempo para tomar la lección. Las cuestiones más importantes o controvertidas, que marcaban diferencias de escuela, se profundizaban mediante la disputalio o disputas, que constituían generalmente actos solemnes y hasta públicos de singular importancia. En todo este proceso era 
obligatorio el uso de la lengua latina, que si bien los catedráticos dominaban, en boca de los alumnos dejaba mucho que desear. Manuel del Socorro Rodríguez, con ocasión de unas conclusiones sobre derecho público, sostenidas por vez primera en castellano el 4 de julio de 1771 en contra de la inveterada costumbre, hace un alto elogio de la lengua castellana:

\begin{abstract}
En hora buena el antiguo idioma de los romanos se cultiva entre nosotros con la aplicación que merece su hermosura, energía y dignidad...; pero sea dejándole un lugar muy distinguido a la lengua materna, que es lo que más nos honra y nos deben inspirar las leyes de un sólido y perfecto patriotismo. La sabiduría no tiene lengua propia, porque todas son suyas; $y$ si en alguna se puede explicar con propiedad característica de su ser, es en aquella en que el hombre nace... Y eso es de muy pocos sujetos: porque los más ignoran el modo de explanar sus raciocinios en un discurso castellano medianamente compuesto, y no pocas veces se experimenta que ni aun en un ordinario latín (Rodríguez, 1982).
\end{abstract}

Ciertamente, frente a una Europa deslatinizada en gran medida (Kant todavía escribe sus primeros trabajos escolares en latín por este tiempo), era un anacronismo que se siguiese hablando y escribiendo en latín en una lejana colonia. A la dificultad del latín se sumaba el uso y abuso del silogismo, por lo que los ilustrados del Nuevo Reino motejarán a sus maestros de "ergotistas”. De la Universidad, escribe, no sin exageración, Antonio Zea: "ha salido un torrente de ergotistas, cuya confusa gritería no dejaba escuchar la voz de la razón" . A ello se añadía la excesiva importancia del argumento de autoridad y el enconado espíritu de escuela o partido. Para completar este cuadro un tanto negativo, en la segunda parte del siglo XVIII, los ilustrados neogranadinos achacarán a la escolástica la discusión de cuestiones inútiles, en desconocimiento de los problemas reales del país, objeto de las "ciencia útiles".

Sin embargo, las críticas de los ilustrados (como más tarde la de las liberales) no siempre en todos los puntos fueron justas. Aun con los anteriores defectos, hoy queda un total de más de doscientos manuscritos de los siglos XVlI y XVIII, que dan fe de que la filosofía se cultivó seriamente, "formaliter", cosa que no volvió a ocurrir en nuestra historia hasta bien entrado el siglo XX. Esta producción está aún por estudiar para acercarnos a una apreciación más justa. Bastantes tratados son de lógica,

3 Zea, Antonio, Ibíd. 
campo en el que se pueden presentar algunas sorpresas de interés positivo. Sabemos hasta qué punto la lógica moderna (que en contra de lo que pensó Kant, dio grandes pasos adelante) justiprecia hoy muchos de los hallazgos de la lógica escolástica. De filosofía política y del derecho existen manuscritos "de justitia et iure" que prolongan, sin duda, los brillantes desarrollos de la segunda escolástica y que habría que desempolvar y estudiar. Según algunos estudiosos de este campo, nuestros ilustrados y emancipadores dependen en su ideología, más que de las fuentes ilustradas, del iusnaturalismo español que defendió, entre otras tesis de interés, la soberanía popular'. Vitoria, Cano, Suárez, Mariana y otros constituían autoridades muy apreciadas, junto a Aristóteles y Tomás de Aquino. La ética y la teología natural se estudiaban como parte de la teología. En ética, la cuestión del justo precio tuvo desarrollos muy importantes, por ejemplo, en el hispano-mexicano Tomás de Mercado que escribió la célebre Suma de tratos y contratos (1569), citada por los nuestros. Sería interesante conocer más a fondo las doctrinas psicológicas y las que se refieren a la naturaleza del conocimiento. En este punto no todo es baladí en el pensamiento tomista y escotista, antes bien alcanza grandes profundidades. Sabemos que en muchos puntos la segunda escolástica, sobre todo Suárez y su escuela, llegó a defender tesis originales, que aún hoy no han perdido actualidad.

Difícil cuantificar la producción filosófica colonial por materias, pues como ya dijimos muchas de las especulaciones filosóficas están integradas en los cursos de teología y en los comentarios a la Summa Theologica de Santo Tomás o de otros cabezas de escuela como Duns Escoto y Suárez. Pero tentativamente podemos dar las siguientes cifras, lógica: 16 tratados; física: 13; antropología o psicología racional: 5; metafísica: 9; teología o teodicea: 44; moral o ética: 11; derecho: 7.

Los títulos de cursos y comentarios nos pueden dar una idea de la problemática colonial. He aquí algunos que se repiten:

- Lógica: Lógica parva et magna, Institutiones dialecticae.

- F. Naturaleza: In Physicam, Philosophia naturalis, In octo physicorum Arilstotelís libros, De genemtione et corruptione.

- Psicología Racional: De anima, De sensu et sensato.

- Metafísica: In metaphysicam, Disputationes metaphysicae, De causis.

4 Gómez Hoyos, Rafael. La revolución granadina de 1810. Ideario de una época, 2 vols., Biblioteca de Cultura Hispánica, Bogotá, 1962. 
- Etica: De conscientia, De actíbus humnnis, De virtutíbus et peccatis, De beatitudine.

- Derecho: De Lege, De iustitia et iure, De íniustitiis, De contratíbus.

- Teología natural: De essentia e natura Dei, De Deo uno, De atríbutibus Dei, De scientia et voluntate Dei, De praedestínatione et reprobatione, De providencia divina, De auxíliis.

Entre los cursos completos de filosofía hubo dos que gozaron de especial reconocimiento: uno, el de Antonio Goudin, O.P. Philasophia thomistica justa inconcussa tutissímaque Divi Thomae dogmata quattor tomis comprehensa, Matriti, 1693, que estuvo por muchos años como texto de consulta en la Universidad tomista, y de la cual se conservan apuntes o resúmenes de los alumnos en los archivos. Otro, la obra de orientación suareciana de Juan Martinez de Ripalda, S.J. De Usu et abusu doctrinae Divi Thomae, como dijimos publicada en Lieja en 1704, y que fue sin duda texto apreciado en la Javeriana hasta la expulsión de la Compañía. Las disputas o controversias entre las principales corrientes escolásticas (tomísmo, surecianismo y escotismo) debieron ser agitadas, aunque todos reclamaban para sí la fidelidad a Aristóteles y Santo Tomás y la acertada explicación de los respectivos textos, al tiempo que destacaban los desaciertos hermenéuticos de las otras escuelas en puntos de fricción, con frases como estas: sententiae oppositae suis viribus examantur; expenduntur quae contra militant; argumenta thomisticne et scotisticae sententiae expediuntur; variis rationibus Thomistíca schola reícitur; etc. Dado que estaba prescrito enseñar la doctrina de Santo Tomás y que los dominicos consideraban que la doctrina de Suárez se apartaba de tradicional, Ripalda pone sumo empeño en demostrar que la Javeriana sigue la verdadera doctrina de Santo Tomás, mientras que los profesores de la tomista usan y abusan de la misma puríoris doctrinae zelo. Haciendo alusión a la enconada controversia sobre el derecho a otorgar grados que sostuvieron las dos universidades durante el siglo XVII, Ripalda se pregunta y responde:

\footnotetext{
¿Acaso en nuestra Universidad (Xaveriana) no se sigue la doctrina de Santo Tomas? Ciertamente, la autoridad del Angélico Maestro fue recomendada grandemente por nuestro primer Padre San Ignacio, y siempre estuvo en gran estima y veneración en nuestras escuelas... Yo no solamente he cultivado la doctrina del Maestro Angélico con ahínco; sino que por la misma he luchado sinceramente y por amor a la verdad, hasta asumir los trabajos más ímprobos ${ }^{5}$.
}

5 Martínez de Ripalda, O.C., "Praefatio". 
Además de Juan Martínez de Ripalda, podernos considerar como catedráticos eminentes de las universidades coloniales, entre los jesuitas a Jerónimo de Escobar, José de Urbina, Juan Antonio Varillas, Manuel Balzategui, Luis Chacón, Francisco Escobar, Mateo Folch, Juan Francisco Granados, Mateo Mimbela, José Yarza; entre los dominicos a Agustín Manuel Alarcón y Castro, Juan José Bonilla, Jacinto Antonio Buenaventura, Francisco Antonio Cabrejo, Francisco Guelga, Rafael Mancera; entre los franciscanos, Pedro Ceballos, Jerónimo Marcos, Ignacio Antonio Parrales.

Hubo un aspecto en la filosofía colonial que constituyó piedra de escándalo. Las filosofías, ha escrito acertadamente Etienne Gilson, "envejecen por la cosmología". En efecto, la "imago mundi", que la escolástica colonial del siglo XVII sustenta, era la vieja y ya caduca física peripatética, que la ciencia moderna había mandado recoger. Por su recelo a lo nuevo, en tanto que se juzgaba un peligro para la fe, España perdió contacto con los desarrollos de la "nueva ciencia" $y$ de aquí, en parte, su relativo atraso que trató tardíamente de remediar el pensamiento ilustrado peninsular, del cual es reflejo el nuestro. Sin embargo, junto al pensamiento tradicional se fue durante el siglo XVIII conociendo el de los modernos. ¿Cómo fue esta lenta recepción? Habría que investigarla en los manuscritos mismos. Por ejemplo, hoy sabemos que no fue Celestino Mutis el primero que en el Nuevo Reino expuso ante los ojos atónitos de los neogranadinos el sistema de Copérnico, como habitualmente se dice. Mutis llega a Santa Fe en 1760. Pues bien, en una Physica specialís et curiosa, de 1757, de anónimo jesuita profesor de la Javeriana, se da a conocer el heliocentrismo o sistema de Copérnico tres años antes que Mutis.

Descartando, quizás, grandes sorpresas, los historiadores de las ideas, mediante paciente estudio de este valioso legado colonial, que constituyen más de 200 manuscritos, pueden encontrar otros aspectos de importancia que hagan justicia a la historia.

\section{Algunas consideraciones metodológicas}

$\mathrm{Si}$, para terminar, echamos una mirada a algunas interpretaciones que de la colonia, y en especial de la filosofía colonial, se han dado, salta a la vista que han estado viciadas por intereses ideológicos, políticos y, más aún, partidistas. Dice Bernardo Tobar Zambrano: "La manipulación del material histórico está sobre determinado, ante todo, por las exigencias del momento presente. Estas historias ven lo que desean ver” (Tobar, 1984, p. 101). No lo que en realidad fue la filosofía colonial y la propia 
sociedad, de la cual era expresión y reflejo. Nos tendríamos que preguntar cómo 'la vivieron ellos en su momento y no cómo nos parece a nosotros de cara a legitimar nuestro momento presente. De este efecto adolece, en primer lugar, la visión críticonegativa de la historiografía liberal del siglo XIX durante el período de las reformas liberales, en tanto que proyecto histórico del Partido Liberal. Desde este proyecto "civilizatorio", así al menos lo entendían, la colonia por contraposición les parecía "barbarie" que debía quedar atrás y ser negada.

Por el contrario, la historiografía conservadora desde antes de la Regeneración, pero especialmente en este período clave de la historia colombiana, pretendió conservar a toda costa la herencia hispana colonial, como base de su proyecto político, refiriéndose a la misma en términos encomiásticos de sobreestimación. En ambos casos, el rechazo rotundo y la apología desmedida obedecían a motivos extrínsecos y a intereses extraños a la historia misma. De ahí sus limitaciones y el poco interés que mostraron unos y otros por el conocimiento del pasado tal como lo vivieron los propios protagonistas.

La nueva historia de Colombia ha ido subsanando tales desenfoques decimonónicos, llegando a conclusiones más equilibradas y objetivas. Por lo que hace a la historia de las ideas en la época colonial apenas estamos empezando a estudiarla con este nuevo espíritu que manifiesta la actual historia social. Nos merecen especial aprecio los trabajos de Jaime Jaramillo Uribe $^{6}$ por su documentado tratamiento y su equilibrio interpretativo, tan distante de los extremos señalados. Pero al parecer aún no estamos curados del todo de los mismos. Para no citar sino dos casos recientes, Víctor Frankl, por los años cuarenta profesor en la Universidad Nacional, en su obra Espíritu y camino de Hispanoamérica ${ }^{7}$ nos quiere retrotraer a la Edad Media, “época juvenil de la cultura", frente a la época moderna y contemporánea que las percibe como decadentes. En el extremo contrario habría que situar el reciente trabajo de Renán Silva: Saber, cultura y sociedad en el Nuevo Reino de Granada (siglos XII y XVIII) ${ }^{8}$, muy documentado y crítico, pero que adolece a nuestro parecer del mismo defecto extrinsecista, consecuencia de la metodología foucaultiana que emplea. En este caso

6 Cf. Jaramillo Uribe, Jaime, en La Filosofía en Colombia, Bibliografía del siglo XX Biblioteca Colombiana de Filosofia, Bogotá, 1984, pp. 64-67.

7 Frankl, Víctor, Espíritu y camino de Hispanoamérica, Biblioteca de Autores Colombianos, Bogotá, 1953.

8 Silva, Renán. Saber, cultura y sociedad en el Nuevo Reino de Granada (siglos XVII y XVIII), Universidad Pedagógica Nacional, Centro de Investigaciones, Bogotá, 1984. 
los textos son interpretados como una arqueología de saber sin otro espíritu que el de reproducir la ideología del sistema al cual sirvieron, vigilar y castigar. Es un modelo de estudio de la historia desde nuestro momento presente por antipatía.

La historia, que constituye nuestra tradición, hay que asumirla, por supuesto críticamente, pero sin fetichismo, ni maniqueísmo de una u otra especie. Hay que crearla por dentro en busca del hilo conductor de sentido que para sus protagonistas tuvo. Solo así podremos entender el presente en el que, gracias a las posibilidades que nos legó el pasado, estamos hoy instalados.

Como punto final a estas consideraciones, tengo la satisfacción de poner en manos de los asistentes a este VIII Coloquio de la Sociedad Colombiana de Filosofía, que tanto nos ha honrado al otorgamos la sede del mismo, el libro del profesor e investigador Rafael Pinzón, titulado La filosofía en Colombia, Bibliografía de los siglos XVI, XVII y XVIII. Estoy seguro de que constituye un valioso instrumento para futuras investigaciones de la filosofía colonial en Colombia, que la justipreciarán en lo que vale como filosofía rigurosa y como ideología de una sociedad tan distinta y distante a la nuestra, pero que no por ello carece de interés y sentido.

\section{Referencias}

Pacheco, J. (1971). Un amigo de Descartes. En Historia Extensa de Colombia, 1, 273283. Bogotá: Lerner.

Rodríguez, M. (1982). Filosofía de la ilustración en Colombia. Bogotá: El Búho.

Tobar, B. (1984). La colonia en la historiografía colombiana. Bogotá: La Carreta. 